\title{
Research
}

\section{The Impact of Resource Scarcity on Bonding and Bridging Social Capital: the Case of Fishers' Information-Sharing Networks in Loreto, BCS, Mexico}

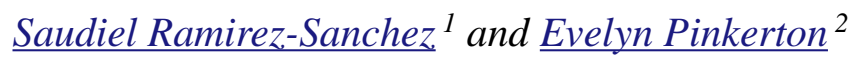

\begin{abstract}
Fishers often rely on their social capital to cope with resource fluctuations by sharing information on the abundance and location of fish. Drawing on research in seven coastal fishing communities in Loreto, Baja California Sur, Mexico, we examine the effect of resource scarcity on the bonding, bridging, and linking social-capital patterns of fishers' information-sharing networks. We found that: (1) fishers' information sharing is activated in response to varying ecological conditions; (2) resource scarcity is an ambiguous indicator of the extent to which fishers share information on the abundance and location of fish within and between communities; (3) information sharing is based on trust and occurs through kinship, friendship, and acquaintance social relations; (4) friendship ties play a key and flexible role in fishers' social networks within and between communities; (5) overall, the composition of fishers' social networks follows a friendship>kinship>acquaintance order of importance; and (6) the function of social ties, internal conflict, and settlement histories moderate the effects of resource scarcity on fishers' social capital. We conclude by arguing that the livelihoods of fishers from Loreto have adaptive capacity for dealing with fish fluctuations but little or no proactive resilience to address resource-management issues.
\end{abstract}

Key Words: Baja California Sur; bonding and bridging social capital; fishers' information-sharing networks; resilience; social network analysis

\section{INTRODUCTION}

The viability of small-scale fishers' livelihoods depends not only on the availability of fish but also on fishers' social capital or social relations that support fishers' adaptive responses to resource fluctuations, external shocks, and other uncertainties (Allison and Ellis 2001). In particular, fishers may engage in information exchanges to reduce the uncertainties and financial risks involved in the decisions about where and when to fish (Andersen and Wadel 1972, Stiles 1972, Acheson 1981, Gatewood 1984, Salas and Gaertner 2004). Trust, here termed social capital, is a key asset enhancing the coping capacity of rural livelihood strategies, especially in the way it affects sharing of information. However, our understanding of what patterns social capital is still incomplete (Bebbington 1999), despite a growing interest by some resilience theorists arguing for a network approach to tease out the structural characteristics that make social-ecological systems resilient (Bodin et al. 2006, Janssen et al. 2006). This question also intrigues co-management scholars, who have tended to focus more on trust building and rule making in local and regional bodies than on larger networks of trust and on how the patterns of these networks enable or constrain collaborative arrangements and collective action (Carlsson and Sandström 2008).

Rather than examining the impact of social capital on social and ecological outcomes, we choose here to focus on factors that affect the production and distribution of social capital itself, an equally important and related area of inquiry (Lin 2001). Specifically, we examine the effect of resource scarcity on the bonding, bridging, and linking social-capital patterns of fishers' networks of seven coastal communities of the Loreto municipality, Baja California Sur (BCS), Mexico. We hypothesize that resource scarcity decreases the 
tendency of fishers to share information on the state and location of fish, making their information networks less dense or bonding within their communities, and that resource scarcity also creates an incentive for fishers to migrate to areas of greater resource abundance, leading to the creation of linking social capital or intercommunity ties. We then look at the respective contributions that kinship, friendship, and acquaintance relationships make to the composition of bonding, bridging, and linking social capital, starting with the hypothesis that there is a kinship>friendship>acquaintance order of importance. Finally, we reflect on the implications such patterns may have for the resilience of fishers' livelihoods and collective action.

\section{Resource Scarcity and Fishers' Social Capital}

It is commonly assumed that social capital is produced by people's interactions and networking based on a self-interested maximization of access to resources (Lin 2001; see also Kadushin 2004 for a review). This assumption is useful for hypothesizing the impact that resource scarcity has on fishers' social capital within and between communities. Within communities, we distinguish between bonding and bridging social capital, and between communities, we adopt the concept of linking social capital. Bonding social capital refers to social cohesion within communities or socially densely connected groups, whereas bridging social capital refers to distinct groups loosely or weakly connected (Putnam 1993, Pretty and Ward 2001, Newman and Dale 2005, Crowe 2007). Linking social capital refers to intercommunity connections (Crowe 2007) and/or community links with external agencies (Sanginga et al. 2007). We adopt these distinctions because they have been used to hypothesize positive and negative effects of social capital on individuals and groups (Portes 1998, Burt 2001, Sanginga et al. 2007). However, we propose five hypotheses about how resource scarcity impacts these different types of social capital.

Stock decline or resource scarcity has been widely documented as a condition motivating competitive behavior (Gordon 1954, Gatewood 1984). It is reasonable to hypothesize from ethnographic accounts that resource scarcity provides a strong incentive for fishers to conceal rather than share information (Andersen 1972). Therefore, we propose the following hypothesis:
$\mathrm{H}_{1}$ : The network structure of information sharing within a community facing relatively high resource scarcity will be less bonding than a community facing relatively low resource scarcity.

The practice of information exchange also has a normative dimension (Truex 1981). Thus, many scholars find that fishers are likely to exchange information more frequently with closely related individuals following a kinship >friendship> acquaintance order of importance (Stiles 1972, Gatewood 1984, Taylor and Singleton 1993, Aswani 2002). Generally, kinship and friendship ties tend to be regarded as strong, whereas acquaintance ties are normally portrayed as weak normatively (Truex 1981, McPherson et al. 2001). Thus, our second and third hypotheses state that:

$\mathrm{H}_{2}$ : When a community faces relatively high resource scarcity, kinship ties will account for most of the social capital within that community, and

$\mathrm{H}_{3}$ : Kinship and friendship ties will similarly account for the social capital at the community level when fishers face relatively low resource scarcity, and acquaintance ties will be relatively low or absent, particularly within relatively small communities.

Geographic mobility for the purpose of accessing fish is a widespread practice (Johnson and Orbach 1990, Curran and Agardy 2002), and a key coping strategy of fishers for dealing with resource fluctuations (Allison and Ellis 2001). Linking social capital in the form of intercommunity ties is critical to this coping strategy. Moreover, linking social capital should be dominated by acquaintance ties, given their associated utility in connecting distinct groups and providing non-redundant resources (Granovetter 1983). Therefore, we propose two hypotheses:

$\mathrm{H}_{4}$ : Linking social capital is more likely to develop between a community facing relatively high resource scarcity and a community with relatively low resource scarcity; and

$\mathrm{H}_{5}$ : Acquaintance ties are most likely to constitute linking social capital. 


\section{Study Area}

The Loreto municipality is located on the eastern side of Baja California Sur, Mexico, and contains several small (100 to 200 individuals) rural coastal communities (Fig.1). These communities often emerged from temporary fishing camps, which gained population in the 1970s, and their relationships are predominantly consanguineal (blood), affinal (marriage), or fictitious kin ("compadre"). Commercial small-scale fishing of clam, conch, octopus, squid, crustaceans, shark, and finfish has been their most important activity (Gutiérrez-Barreras 2001).

The fisheries system in the Loreto area is characterized by a weak regulatory regime, highly resource-dependent livelihoods, weak development of social organizations, extreme poverty, and signs of overexploitation of fish stocks. Despite the rapid growth of tourism and the service sector in the Municipality of Loreto, fishing continues to be the main, and often only, economic activity available in most of the rural coastal communities (GutiérrezBarreras 2001). The social network data that we present in this article are from fishers who reside in the communities of Ramadita, San Nicolás, Colonia Zaragoza, Juncalito, Ligüí, Ensenada Blanca, and Agua Verde, which were selected because of their strong dependence on small-scale fisheries.

Practically all the coast in this area is easily accessible by a main road. However, three communities considered (Ramadita, San Nicolás, and Agua Verde) are connected only through backroads that tend to get severely damaged during the rainy season. In these less accessible areas, fisheries decline seems to be less pronounced than in areas more accessible by the main road (Hollister 1996, Leal-Jiménez et al. 2003, Ramirez-Sanchez 2007).

\section{METHODS}

In 2005, a survey questionnaire was given to fishers to determine the extent to which fishers consult among themselves to obtain trustworthy information on the state and location of fish (the complete version of this survey questionnaire can be found in Ramirez-Sanchez (2007)). We interpret trustworthy information as that provided "in good faith according to the best of competence" where opportunism is limited or absent (Noteboom
2007:35). The ties reported by these fishers constitute the social network data we analyze, supplemented by insights from informal interviews. Two questions were asked: who do you consult to obtain trustworthy information regarding abundant fishing areas in (1) your community, and (2) six other rural fishing communities in Loreto municipality? For the first question, each fisher was presented with a list of fishers from his community and, for the second, the fisher was asked to name his personal contacts from the other communities. In addition, fishers were asked to report on whether the reported contacts were kin, friends, or acquaintances.

There are several network metrics to assess social capital. Borgatti et al. (1998) identify several standard network metrics, which they classify considering the unit of analysis (the individual vs. the group) and the conceptual focus (internal vs. external group links) of social capital. More recently, Crowe (2007) developed an integrated framework that evaluates the bonding and bridging aspects of social capital within communities. Given our interest in social capital at the community level, we chose Crowe's framework to evaluate bonding and bridging social capital within each of our study communities. To assess linking social capital we adopt Crona and Bodin's (2006) approach, which consists of finding the proportion of observed vs. expected ties.

Crowe conceptualizes bonding and bridging social capital within a community network as a matter of degree (not as a difference in kind) along a denseloose scale. Using this scale, Crowe defines two bonding and two bridging network structures. A "complete" network in which every member is connected to every other member marks the upper limit of a bonding network structure. A "factional" network also represents a bonding structure and consists of two or more densely connected groups that are not connected to each other. The more loosely connected a network is, the more it resembles a bridging network structure. Crowe (2007) defines two kinds of bridging networks: coalitional and bridging. Densely connected groups that are connected to one another in a non-redundant manner represent a "coalitional" network. Finally, at the loose end of the scale lies a "bridging" network structure, which is a sparsely connected network. In our study, we did not consider the "factional" network structure because all community networks were fully connected. 
Fig. 1. Location of fishing communities studied: (1) Ramadita; (2) San Nicolás; (3) Loreto; (4) Colonia Zaragoza; (5) Juncalito; (6) Liguií; (7) Ensenada Blanca; and (8) Agua Verde. Municipalities in the state of Baja California Sur: (I) Loreto; (II) Mulegé; (III) Comondú; (IV) La Paz; and (V) Los Cabos.

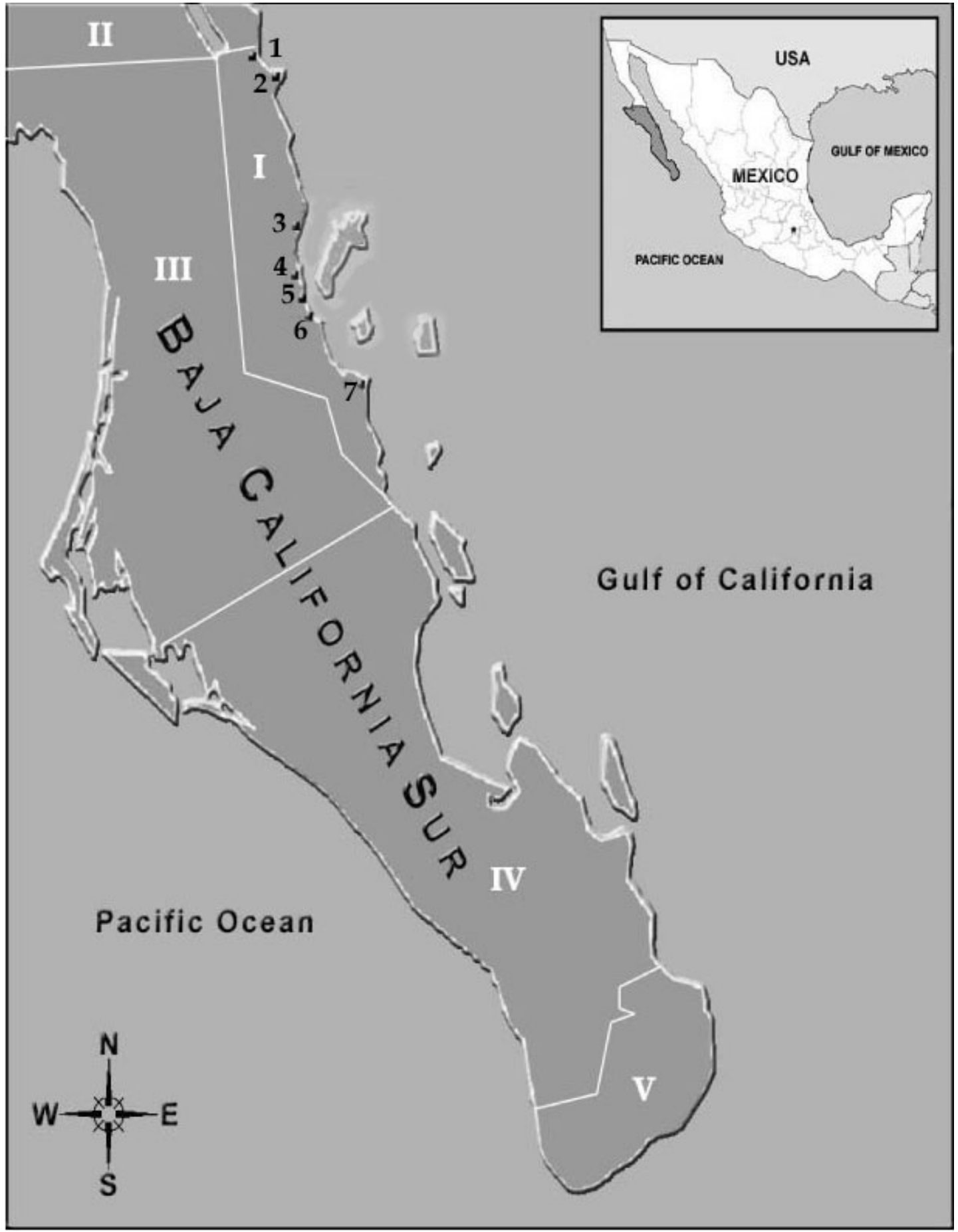


We use $k$-cores and cut-points network metrics (Crowe 2007) to determine the extent to which each community network resembles a complete, coalitional, or bridging structure (Fig. 2). A $k$-core is a sub-network in which each fisher is directly connected to at least a minimum number, $k$, of the other fishers in the network. For example, a fisher with direct ties to two other fishers is a 2-core and so on. Thus, a network with relatively high $k$-cores will be more cohesive than a network with low $k$ cores. A cut-point in a network is a fisher that, if removed, would fragment a network into two or more sub-networks (termed "blocks" in the network analysis literature) among which there are no connections.

To assess linking social capital among communities, we follow Crona and Bodin's (2006) approach, which consists of calculating the ratio of measured vs. expected relations within and between communities using a relational contingency table analysis (Borgatti et al. 2002). The expected number of relations is that expected by chance alone of a network of equal size and number of ties. Applied to our seven study communities, the relational contingency table analysis provides the ratios of measured vs. expected relations within each community and between all pairs of communities. We use the ratios between communities as indicators of the strength of the linking social capital. We use the UCINET suite of social networks programs to determine all network properties considered (Borgatti et al. 2002). In addition, we use network visualizations created using Netdraw (a program distributed by UCINET).

\section{RESULTS}

Our assumption that fishers' sharing of information informs fishers' decisions about when and where to fish comes from observations made during a first visit to the area in 2001. Fishers were often observed consulting with one another on the state of fishery resources and fishers recounted times when they would temporarily leave their communities to fish in other areas after a fellow fisher had informed them about a good fishing opportunity elsewhere.

\section{The Activation of Fishers' Social Networks}

Informal interviews and participant observation revealed that fishers' social networks: (1) are activated in relation to fluctuations in resource abundance and (2) emerge from trustworthy interpersonal exchanges of information embedded in kinship, friendship, and acquaintance relations. Although many factors may affect fishers' reliance on social networks to learn about the abundance and location of fish, social networks are typically used during transitions in fish abundance (from no or low abundance to sudden increases). Initially, some fishers may take the risk of going out fishing to assess the state of fish stocks. Those who wait on land and have trustworthy relations with those who have taken the risk of going out fishing will contact these fishers to obtain firsthand information on the state and location of fish and then decide whether or not to go out fishing at the next opportunity. Exchange of information through social networks may decline during higher abundance of fish, and the content of information sharing may change from the overall state of fish stocks to particular locations where fish have been found. For instance, in 2005, a fisher from Liguií commented "when I find abundant fish, I share their location with others, but when the fish are not that abundant, I share this information only with a few."

Informal interviews and participant observation also revealed that a common response of fishers to fluctuations in fish abundance is to migrate to other locations to access fish. Here, direct personal contacts with members of other communities are used to decide whether or not to temporarily migrate. Fishers in communities where resource scarcity is moderate are less likely to migrate and often host family, friends, and acquaintance fishers from other areas. Indeed, the proportion of fishers from the four communities considered in this study that can be easily accessed from the main road reported more frequent migrations than fishers from the three communities with difficult access (Fig. 3). This pattern is consistent with what fishers from communities adjacent to the main road reported about the scarcity of fish (Hollister 1996, LealJiménez et al. 2003). 
Fig. 2. Description of three network structures according to $k$-cores and cut-points network metrics along a dense-bonding/loose-bridging continuum.

COMPLETE

High proportion of fishers in relatively high

$k$-cores, and no cut-points or very low proportion of cut-points to total number of points (fishers) of the network
High proportion of fishers in relatively high $k$-cores, and high proportion of cut-points
Low proportion of fishers in relatively high $k$-cores, and Low proportion of cut points
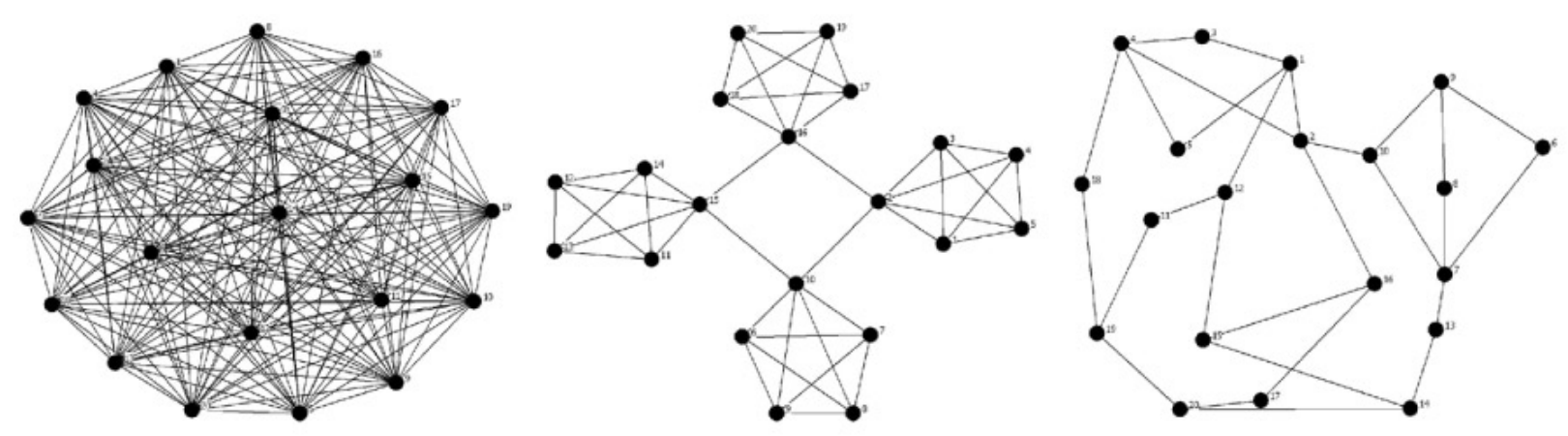

Dense

Bonding

Loose

Bridging

\section{The Social Networks of Information Sharing}

We applied our survey questionnaire to 123 fishers who were members (all males) of households who agreed to participate in our research from the seven coastal fishing communities. These 123 fishers represent $75 \%$ of all households involved in fishing. We report only on the networks among 121 fishers because the other two did not report consulting with anybody regarding the abundance and location of fish. The 121 fishers reported a total number of 638 ties.

Figure 4 shows the overall pattern of the network of information sharing among fishers. A multidimensional scaling (MDS) technique (Borgatti et al. 2002) was used to determine the location of each fisher in this visualization. Although fishers' tend to cluster according to their community affiliation, some communities are more tightly clustered than others. Thus, the fishers from Colonia Zaragoza appear particularly spread apart compared with fishers from Agua Verde, Ligüí, and
Ensenada Blanca. The initial patterns suggested by the network visualization need to be quantified using network properties.

\section{Bonding and Bridging Social Capital}

Table 1 shows the network characteristics of the fishers' information-sharing network by community. Communities were divided into two broad subcategories of low and high resource scarcity. The highest value of $k$ for each of the seven communities (Table 1) ranges from 2 (Juncalito) to 8 (Ligüí and Ensenada Blanca). This means that the highest number of fishers with whom at least one fisher reported sharing information was two within Juncalito and eight in the cases of Liguí and Ensenada Blanca), with the other four communities falling within this range. Thus, we follow Crowe's (2007) rule of using the lowest value in this range to assess community cohesiveness within each community and facilitate comparisons among 
Fig. 3. Fishers who leave their communities temporarily to access fish resources. Ramadita (RM), San Nicolás (SN) and Agua Verde (AV) communities experience lower resource scarcity than Colonia Zaragoza (CZ), Juncalito (JC), Ligüí (LG), and Ensenada Blanca (EB) communities

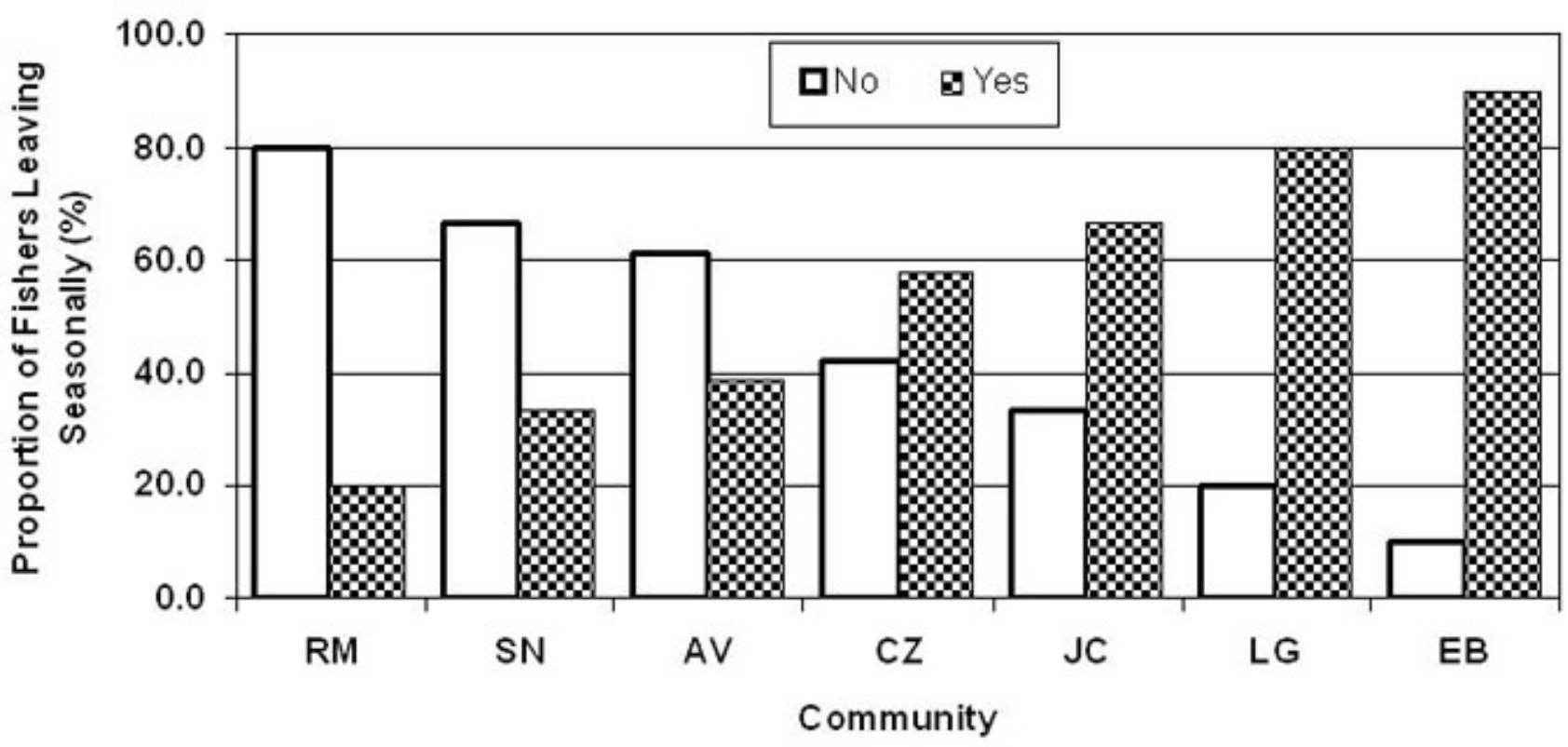

communities. This allows us, following Crowe's work, to use both the $k$-cores and cut-points of each community network to categorize their network structure: complete, coalitional, or bridging (see Fig. 2 for details).

Our first hypothesis $\left(\mathrm{H}_{1}\right)$ that relatively high resource scarcity tends to lower bonding social capital (making it more bridging) is not clearly supported by our results. Two of the communities facing high resource scarcity, Juncalito and Colonia Zaragoza, have a coalitional (bridging) network structure, whereas two of the communities facing low resource scarcity, Ramadita and Agua Verde, have a complete (bonding) network structure. However, Ligüí and Ensenada Blanca communities also show a complete or strong bonding network structure despite facing high resource scarcity, and the San Nicolás community has a coalitional network structure although fishers in this community face relatively low resource scarcity
(Table 1). Therefore, we need to probe further into the differences between these two contrasting patterns.

Table 2 shows the composition of the networks within and between communities and for the whole network in terms of the number of kinship, friendship, and acquaintance ties. Within communities, kinship and friendship ties are rather similar, whereas the number of acquaintance ties is significantly low. Between communities, acquaintance and kinship ties are similar in numbers, whereas friendship ties are significantly high. For the whole network, friendship ties are more numerous than kinship ties and significantly higher than acquaintance ties. Clearly, it is only within communities that the kinship>friendship>acquaintance order of importance appears.

Table 3 shows the network composition for each community. Our second hypothesis $\left(\mathrm{H}_{2}\right)$ that, under 
Fig. 4. Multi-dimensional scaling plot showing the network structure of 121 fishers. The position of each fisher is estimated based on both within-community and between-community ties, and fishers' community affiliation is shown with different shapes and colors. Agua Verde (red circle), Colonia Zaragoza (purple square), Ensenada Blanca (yellow upright triangle), Juncalito (gray box), Ligüí(white downward triangle), San Nicolás (white circle-in-box), and Ramadita (orange diamond).

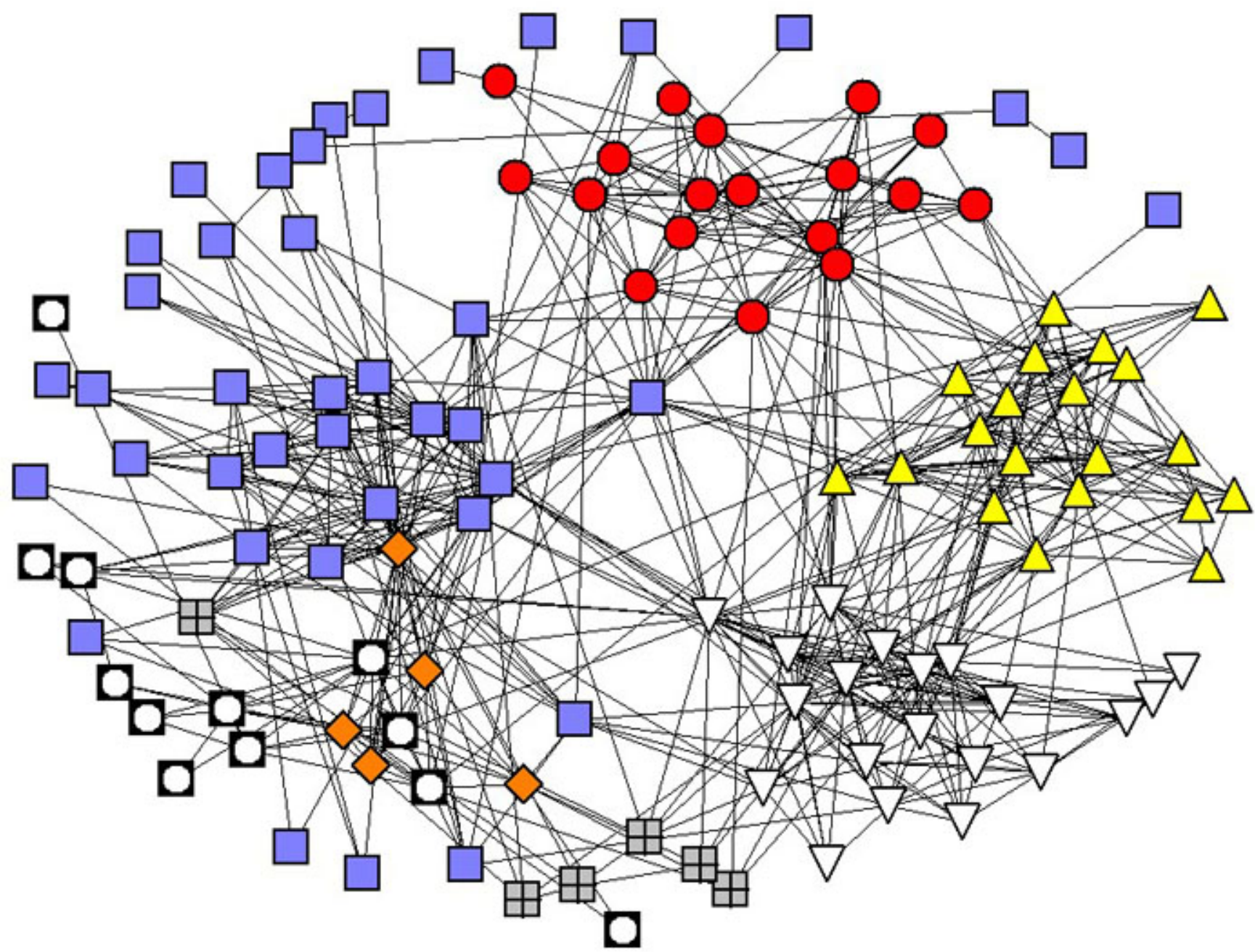

relatively high resource scarcity, kinship ties should account for most of the social capital within communities is only partially supported by our results. Putting Juncalito aside, where "all" information sharing occurs through kinship ties, the other communities show a mixed pattern. Ligüí, Ensenada Blanca, and Colonia Zaragoza (facing high resource scarcity) do not display a relatively large proportion of kinship ties, and in the case of Colonia Zaragoza, the proportion of friendship ties is practically twice that of the kinship ties (Table 3 ). Under relatively low resource scarcity, Agua Verde and Ramadita's kinship and friendship ties contribute similarly to information sharing, and in San Nicolás, friendship ties are more than double the kinship ties. Within all seven communities, acquaintance ties are infrequent or absent as stated in our third hypothesis. Indeed, none of the communities experiencing relatively low resource scarcity (Ramadita, San Nicolás, and Agua Verde) 
Table 1. Summary of fishers' network characteristics.

\begin{tabular}{|c|c|c|c|c|c|c|c|}
\hline \multirow[t]{3}{*}{ Characteristic } & \multicolumn{7}{|c|}{ Community Network (all relations combined) } \\
\hline & \multicolumn{3}{|c|}{ Low Resource Scarcity } & \multicolumn{4}{|c|}{ High Resource Scarcity } \\
\hline & $\mathrm{AV}$ & $\mathrm{SN}$ & $\mathrm{RM}$ & $\mathrm{CZ}$ & $\mathrm{JC}$ & LG & EB \\
\hline \multicolumn{8}{|l|}{ Network data } \\
\hline Number of fishers & 18 & 11 & 5 & 36 & 6 & 20 & 20 \\
\hline Number of components & 1 & 1 & 1 & 1 & 1 & 1 & 1 \\
\hline \multicolumn{8}{|l|}{ Largest component } \\
\hline Number of fishers & 18 & 11 & 5 & 36 & 6 & 20 & 20 \\
\hline Isolated fishers $\dagger$ & 0 & 1 & 0 & 4 & 0 & 0 & 0 \\
\hline \multicolumn{8}{|l|}{ Indicators of network cohesiveness } \\
\hline Largest $k$-core & 6 & 3 & 3 & 7 & 2 & 8 & 8 \\
\hline No. of fishers in largest $k$-core & 13 & 6 & 5 & 12 & 5 & 13 & 15 \\
\hline Proportion in 2-core and higher & 1.00 & 0.83 & 1.00 & 0.72 & 0.83 & 1.0 & 1.0 \\
\hline \multicolumn{8}{|l|}{ Indicators of structural holes } \\
\hline No. of cut-points & 0 & 1 & 0 & 5 & 1 & 0 & 0 \\
\hline No. of blocks & 1 & 2 & 1 & 8 & 2 & 1 & 1 \\
\hline $\begin{array}{l}\text { Proportion of cut-points to total } \\
\text { points }\end{array}$ & 0 & 0.08 & 0.00 & 0.13 & 0.20 & 0.00 & 0 \\
\hline
\end{tabular}

Estimated network configuration

$\dagger$ Isolated fishers within communities reported not to consult fishers within their communities. To determine the bonding and bridging characteristics of each community, isolated fishers were not considered.

have acquaintance ties. All other communities facing relatively high resource scarcity (Colonia Zaragoza, Ligüí, and Ensenada Blanca) have acquaintance ties, albeit in small numbers, except for the relatively small community of Juncalito where all fishers are kin related.

In summary, the network structure within communities suggests that other factors are mediating the effects of resource scarcity on fishers' bonding and bridging social capital, and the effect of resource scarcity on the composition of these networks was not consistent with our assumption of a kinship>friendship>acquaintance order of importance. Only the weak acquaintance relationships fit our third hypothesis that they would be infrequent or absent in communities facing relatively low resource scarcity, and in relatively small communities. 
Table 2. Composition of the fishers' network within and between communities and of the whole network.

\begin{tabular}{llll}
\hline \hline Type of Relationship & \multicolumn{2}{l}{ Network Composition (\%) } & \\
& Within Communities & Between Communities & Whole Network \\
\hline Kinship & $226(5 \%)$ & $49(26 \%)$ & $275(43 \%)$ \\
Friendship & $202(45 \%)$ & $102(53 \%)$ & $304(48 \%)$ \\
Acquaintance & $18(4 \%)$ & $41(21 \%)$ & $59(9 \%)$ \\
Total & $446(100 \%)$ & $192(100 \%)$ & $638(100 \%)$ \\
\hline
\end{tabular}

\section{Linking Social Capital}

The patterns of linking social capital between communities for the whole network are shown in Fig. 5, and by type of social relation in Figs. 6 to 8. The thickness of the links between communities in these figures is proportional to the ratio of measured vs. expected ties calculated for each pair of communities (Appendix 1). Thus, greater line thickness indicates a greater strength of linking social capital between communities.

Our fourth hypothesis $\left(\mathrm{H}_{4}\right)$ that a community facing relatively high resource scarcity is more likely to develop linking social capital with a community with relatively low resource scarcity is supported by our results (Fig. 5). Thus, Liguií, Ensenada Blanca, and Colonia Zaragoza (communities facing high resource scarcity) have links, albeit weak, with Agua Verde which has higher resource abundance. Colonia Zaragoza and Juncalito (communities facing high resource scarcity) have medium to strong links with Ramadita, and Colonia Zaragoza is the only community that has (weak) links with San Nicolás, which has higher resource abundance. It is also worth noting that linking social capital is more widespread than predicted by our hypothesis. Thus, there are weak to medium links between communities facing high resource scarcity (Colonia Zaragoza, Juncalito, Liguií, and Ensenada Blanca), and there is strong linking social capital between two of the communities facing low resource scarcity, Ramadita and San Nicolás.

Our last hypothesis that linking social capital is most likely to be made up of acquaintance relations, is partially supported by our results (see Appendix 1 for details). Thus, relatively weak kinship linking ties do occur mostly among geographically close communities (Fig. 6). In other words, the kinship ties between communities are much smaller than those expected by chance alone in a network of similar size and equal number of ties. In contrast, friendship ties are not only present among a higher number of communities, but they range from weak through medium to strong (Fig. 7), and in the cases of the linking social capital between Ensenada Blanca-Ligüí, Juncalito-Ligüí, San Nicolás-Ligüí, San Nicolás-Juncalito, and San Nicolás-Ensenada Blanca, friendship ties instead of acquaintance relationships dominate linking social capital. To be sure, there is a higher presence of strong (calculated ratios of measured vs. expected ties) acquaintance linking ties between communities (Fig. 8) than friendship or kinship linking ties (see Appendix 1).

In sum, linking social capital is not only likely to develop between a community facing high resource scarcity and a community with high resource abundance, but linking social capital may also develop among communities facing high resource scarcity and among communities with high resource abundance. The hypothesis that linking social capital is more likely to be dominated by acquaintance relationships given their presumed utility in connecting distant groups is partly supported by the strength of these links among communities. However, in several cases, friendship ties instead of acquaintance ties dominated the composition of linking social capital. 
Table 3. Composition of the fishers' network by community.

\begin{tabular}{|c|c|c|c|c|c|c|c|}
\hline \multirow{3}{*}{$\begin{array}{l}\text { Type of } \\
\text { Relationship }\end{array}$} & \multicolumn{7}{|c|}{ Network Composition within Communities (\%) } \\
\hline & \multicolumn{3}{|c|}{ Low Resource Scarcity } & \multicolumn{4}{|c|}{ High Resource Scarcity } \\
\hline & $\mathrm{AV}$ & $\mathrm{SN}$ & $\mathrm{RM}$ & $\mathrm{CZ}$ & $\mathrm{JC}$ & LG & $\mathrm{EB}$ \\
\hline Kinship & $44(57 \%)$ & $6(29 \%)$ & $5(56 \%)$ & $37(32 \%)$ & $8(100 \%)$ & $64(56 \%)$ & $62(54 \%)$ \\
\hline Friendship & $33(43 \%)$ & $15(71 \%)$ & $4(44 \%)$ & $73(63 \%)$ & 0 & $36(31 \%)$ & $41(36 \%)$ \\
\hline Acquaintance & 0 & 0 & 0 & $5(4 \%)$ & 0 & $6(5 \%)$ & $7(6 \%)$ \\
\hline $\begin{array}{l}\text { Total } \\
\text { within } \\
\text { community }\end{array}$ & $77(100 \%)$ & $21(100 \%)$ & $9(100 \%)$ & $115(100 \%)$ & $8(100 \%)$ & $106(100 \%)$ & $110(100 \%)$ \\
\hline
\end{tabular}

\section{DISCUSSION}

Small-scale fishers from the Loreto area reported relying on diverse social ties for sharing information on the state and location of fish resources to inform their decisions about when and where to fish. The information exchanged among these fishers provides a fisher with opportunities and choices otherwise not available for accessing fish. The "extent" to which small-scale fishers from the Loreto area report information sharing is remarkable, given the generalized fisheries decline in the Loreto area in the past 20-30 years, which previous studies suggest should operate as a disincentive for fishers to share information (Gordon 1954, Andersen 1972, Gatewood 1984, Ostrom 1990).

The activation of fishers' communication networks is attuned to varying ecological conditions but is intrinsically based on trust. During the pre-testing of our survey questionnaire, it was found that without the qualifier "trustworthy" ("confianza"), the question about personal contacts seemed almost unintelligible to fishers and resulted in answers such as "anybody in the community will provide you with information." The qualifier "trustworthy" made the question intelligible to fishers and often prompted discussions on resource users who were untrustworthy. Such discussions also revealed the fishers' diversity of social contacts when dealing with resource fluctuations. It is also worth noting that all ties reported by fishers were considered trustworthy, and although different types of social ties (e.g., kinship vs. acquaintance relationships) may vary in their degree of trustworthiness, we did not probe more deeply into this aspect when collecting our data.

However, in the Loreto area, the extent of fisheries decline is not uniform and four out of the seven fishing communities (Colonia Zaragoza, Juncalito, Ligüí, and Ensenada Blanca) we studied face greater resource scarcity than the communities of Ramadita, San Nicolás, and Agua Verde (Hollister 1996, Leal-Jiménez et al. 2003, Ramirez-Sanchez 2007). Based on this condition and assuming that fishers' motivation to engage in interactions and networking is predominantly self-interested, we proposed five hypotheses about the impact that resource scarcity might have on the extent of fishers' social capital within and between communities.

We found mixed evidence that resource scarcity is an important factor affecting the extent of bonding and bridging social capital at the community level (Table 1). In other words, a community facing high resource scarcity may display bonding tendencies comparable to a community facing low resource scarcity, contrary to our first hypothesis $\left(\mathrm{H}_{1}\right)$. Moreover, the composition of the network of information sharing at the community level was not 
Fig. 5. Multi-dimensional scaling plot showing the linking structure among the seven communities. The size of each node (community) is proportional to the number of fishers considered in each community; communities with high resource scarcity are shown with gray circles and communities with low resource scarcity are shown with white circles. The thickness of intercommunity links is proportional to the ratio of the measured vs. the expected number of relations. Thin line $<0.5$ in black, medium line $<1$ in blue, thick line $>1$ in red. Ratio values less than 0.1 were omitted.

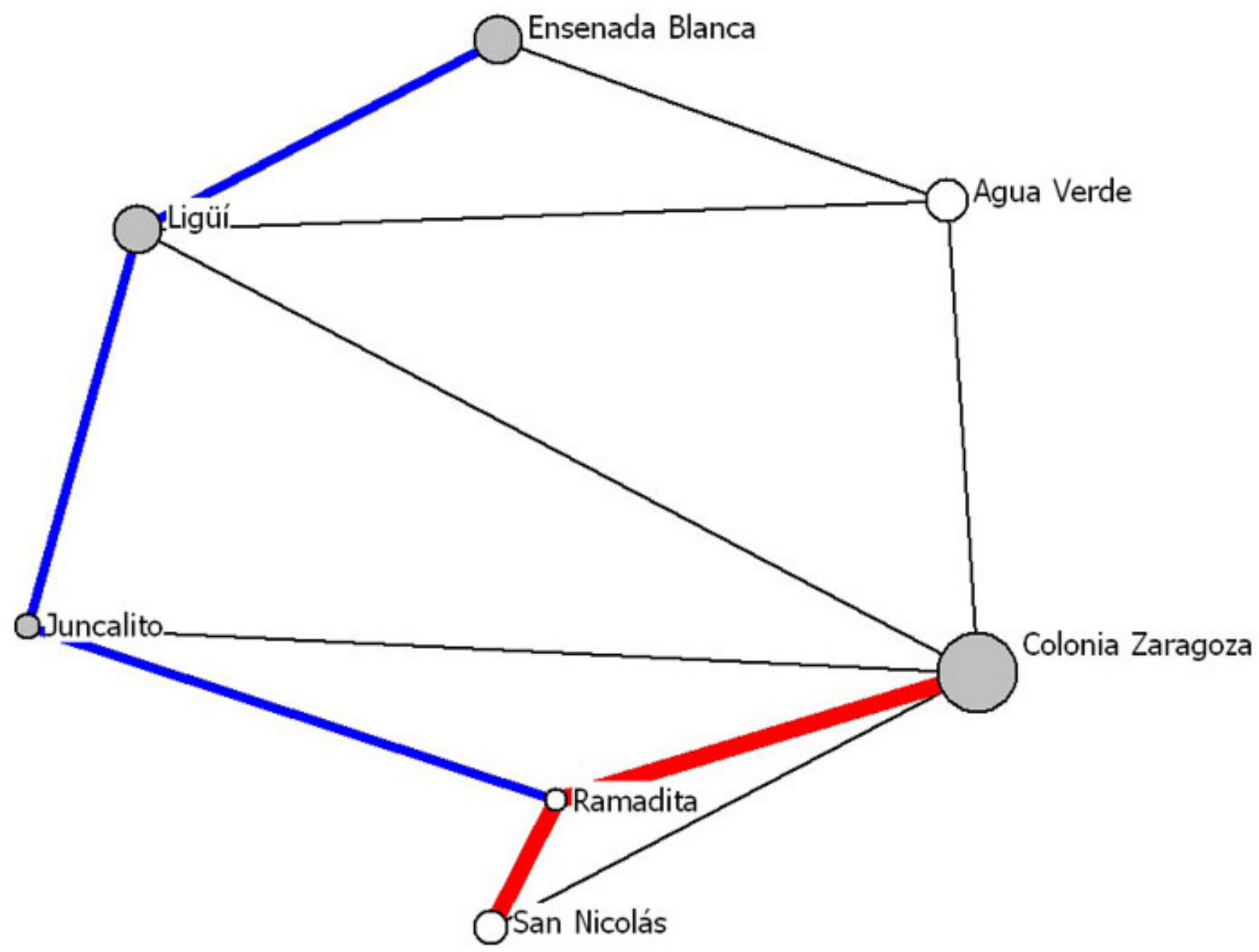

affected consistently by resource scarcity in conjunction with our assumed kinship $>$ friendship $>$ acquaintance order of importance (hypotheses $\mathrm{H}_{2}$ and $\mathrm{H}_{3}$ ). For instance, information sharing seems to occur mostly through friendship relations at the community level whether under high or low resource scarcity (Table 3). Acquaintance relationships, however, were rare or mostly absent in relatively small communities as predicted by our hypothesis $\mathrm{H}_{3}$, which can likely be attributed to the relatively small size of most of our study communities.

Our hypothesis $\left(\mathrm{H}_{4}\right)$ that linking social capital is more likely to form between a community facing high resource scarcity and a community with low resource scarcity, was partially supported by our results. Indeed, linking social capital is more widely 
Fig. 6. Multi-dimensional scaling plot showing the kinship linking structure among the seven communities. The size of each node (community) is proportional to the number of fishers considered in each community; communities with high resource scarcity are shown with gray circles and communities with low resource scarcity are shown with white circles. The thickness of intercommunity links is proportional to the ratio of the measured vs. the expected number of relations. Thin line $<0.5$ in black, medium line $<1$ in blue, thick line $>1$ in red. Ratio values less than 0.1 were omitted.

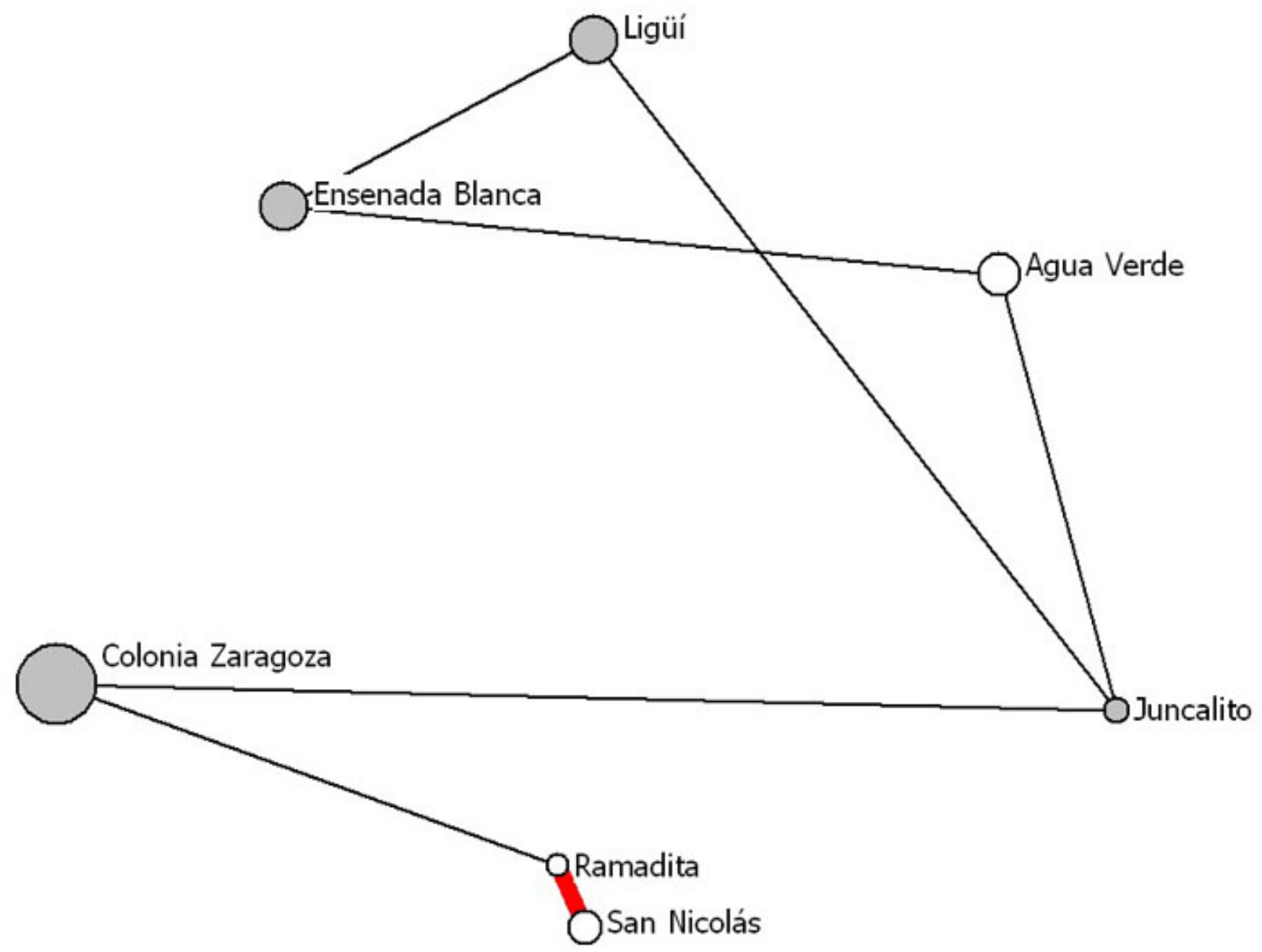

present than our $\mathrm{H}_{4}$ hypothesis based on resource scarcity predicted. The number of linking ties may not be particularly critical for the brokerage function to occur that connects two distinct clusters of actors (Janssen et al. 2006) but it is an important indicator of an adaptive strategy used by fishers for accessing distant resources. Our last hypothesis $\left(\mathrm{H}_{5}\right)$ built on the assumption that the role of acquaintance relations is to connect diverse groups or distant groups and thus that they should dominate linking social capital was partially supported by our results. However, we found that friendship relations can be as important in linking diverse groups as acquaintance bridging ties.

The diverse rather than uniform effect that biophysical factors such as resource scarcity can have on human activities has long been pointed out 
Fig. 7. Multi-dimensional scaling plot showing the friendship linking structure among the seven communities. The size of each node (community) is proportional to the number of fishers considered in each community; communities with high resource scarcity are shown with gray circles and communities with low resource scarcity are shown with white circles. The thickness of intercommunity links is proportional to the ratio of the measured vs. the expected number of relations. Thin line $<0.5$ in black, medium line $<1$ in blue, thick line $>1$ in red. Ratio values less than 0.1 were omitted.

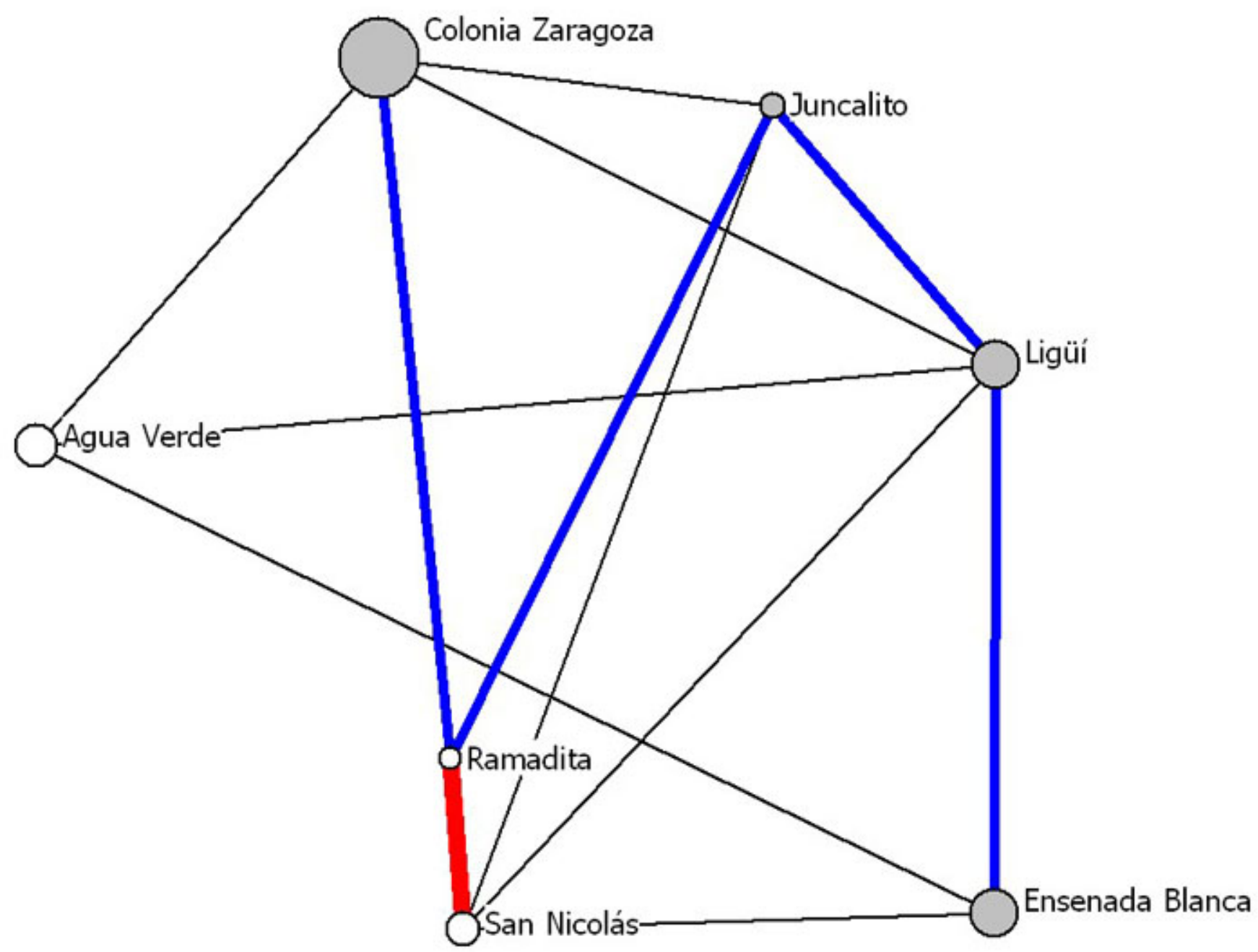

in human-ecological systems, where social factors affect these interactions (McCay 1978). However, we are still learning how social factors mediate these interactions (Curran and Agardy 2002). In further considering our findings, we discuss below the normative and instrumental function of social ties (Granovetter 1983, McPherson et al. 2001), social conflict (Klooster 2000), and settlement histories (Morales-Polo 1994).

\section{Social Ties, Conflict, Settlement History, and Social Capital}

Family and friendship ties have a strong affective/ moral content and weaken slowly compared with other social relations (McPherson et al. 2001). Yet, the seemingly "weak" acquaintance relations may have a "strong" role in bringing integration to social groups. Mark Granovetter's (1973) theory of the 
Fig. 8. Multi-dimensional scaling plot showing the acquaintance linking structure among the seven communities. The size of each node (community) is proportional to the number of fishers considered in each community; communities with high resource scarcity are shown with gray circles and communities with low resource scarcity are shown with white circles. The thickness of intercommunity links is proportional to the ratio of the measured vs. the expected number of relations. Thin line $<0.5$ in black, medium line $<1$ in blue, thick line $>1$ in red. Ratio values less than 0.1 were omitted.

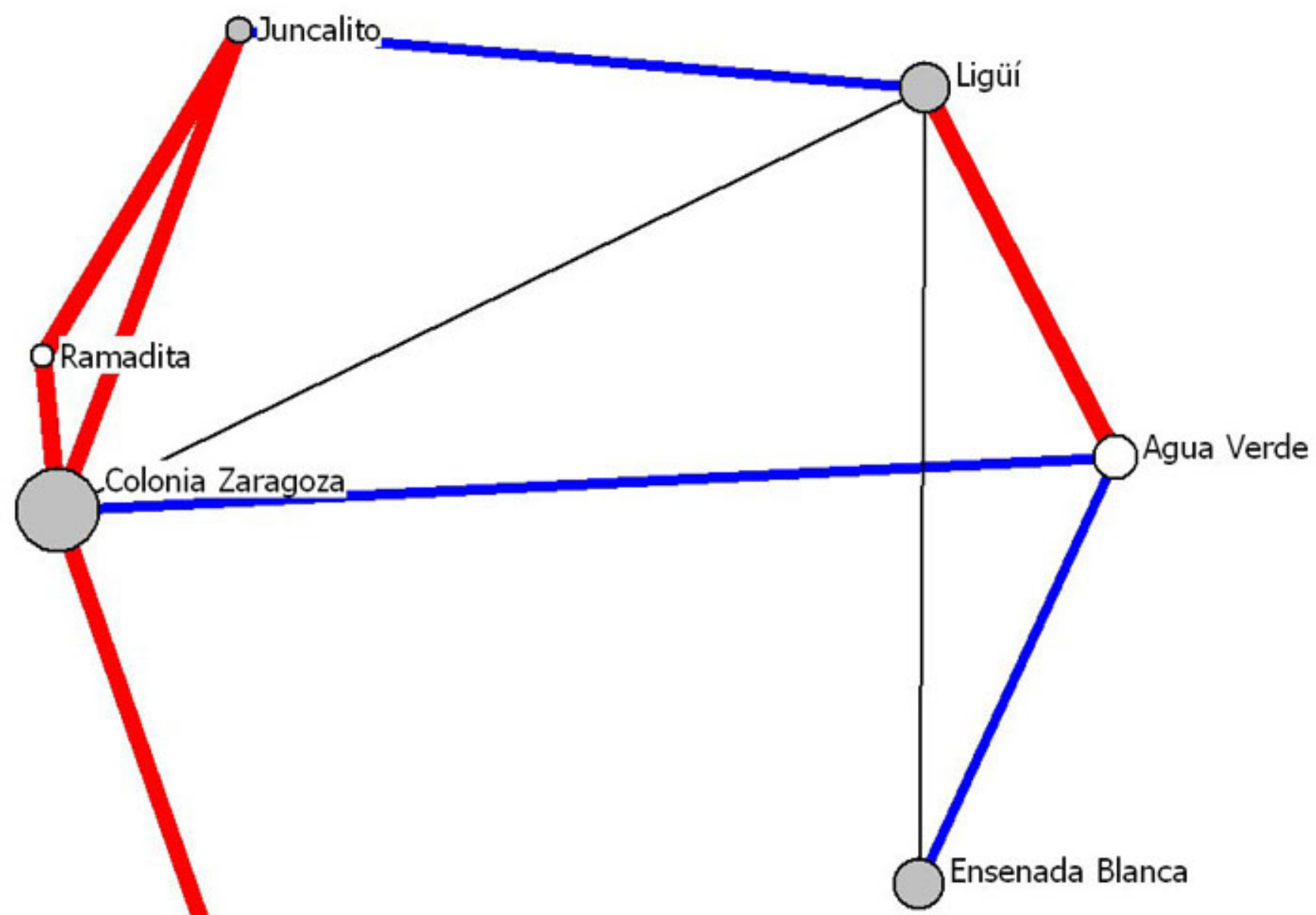

"strength of weak ties" proposes that, under certain conditions, weak relations (i.e., acquaintance relations) may be more critical than strong ties in bridging social groups and avoiding, for instance, redundant information and social fragmentation. That is, weak ties may provide individuals with access to information and resources beyond those available in their own social circles. Yet "strong ties provide greater motivation to be of assistance and are typically more easily available," especially for people who are economically insecure or poor (Granovetter 1983:209). Social ties then have normative and instrumental content that can interact with other social contextual factors.

Most fishers from the coastal communities of Loreto have kinship and affinal relations, which can be explained by the settlement history of Loreto by a 
few families and its low population density (Instituto Nacional de Estadística y Geografía (INEGI) 2001, Morales-Polo 1994). In addition, most fishers in the Loreto area live in precarious economic conditions because of the low value of most small-scale fisheries and lack of sufficient alternative economic activities (Ramirez-Sanchez 2007). The extent of information sharing within communities through kinship ties is higher than that between communities, except for Colonia Zaragoza and San Nicolás communities, which have the lowest ratios of measured vs. expected ties at the community level (see Appendix 1). Interestingly, a second-generation resident from Colonia Zaragoza once claimed, "here, we are all family," yet sharing of information in this location occurs most importantly through friendship relationships. Internal conflict within families may explain the Colonia Zaragoza case, as discussed below.

Klooster (2000) has shown that conflict and corruption are important factors in explaining changes in social systems involved in common-pool resources. In particular, he argues that conflict and corruption may fragment already-stratified communities and disrupt a sense of community based on fairness and legitimacy. In the Colonia Zaragoza community, extended family feuds are frequent and appear to be connected to economic and political conflicts over the management of communal land (Ejido Loreto). Such political and economic conflicts over land may have undermined the normative content of kinship-bonding relationships. Indeed, older fishers from Colonia Zaragoza asserted that 20 to 30 years ago most fishers in the community would share information on abundant fishing areas, but now only a handful will provide trustworthy information. Fishers from the San Nicolás community also tend to share information most importantly through friendship relations. Although there is internal conflict during political elections in this community, the history of settlement may explain why information sharing occurs mostly through friendship relations. In particular, San Nicolás originated with a few families but many other families arrived in recent times from the Mulegé and Comondú municipalities (see Fig. 1). Moreover, most members of the Ramadita community were originally members of the San Nicolás community, which may explain the strong links between these two communities (see Figs. 5-7). In sum, internal conflict and settlement history seem to explain the particular patterns of Colonia Zaragoza and San Nicolás coalitional (bridging) network structure, and low composition of kinship ties at the community level.

Friendship ties are normally associated with bonding social capital or strong normative ties rather than for an instrumental role in linking diverse groups (e.g., DaCosta and Turner 2007, Grafton 2005, Plummer and FitzGibbon 2006). However, we found that friendship and acquaintance relations may be equally important in constituting the linking social capital of fishers from the Loreto area (Appendix 1 and Figs. 7 and 8). Moreover, friendship ties can also be prominent in constituting the social capital at the community level as in the case of the Colonia Zaragoza and San Nicolás communities. In this sense, friendship ties seem to be more normatively malleable than kinship ties and their linking function can be as important as that of acquaintance ties. Indeed, the sheer number of ties in the whole network (Table 2) suggests the overall importance of friendship ties: friendship (304 ties), kinship (275 ties), and acquaintance (59 ties).

Despite the results generated by our study on the impact of resource scarcity on social capital, a larger sample or number of communities would be necessary to make our inferences more robust. Other frameworks such as game theory may also be used to provide alternative hypotheses on the conditions under which fishers' social capital is likely to be affected by resource scarcity when self-interested individuals are assumed. It has to be acknowledged, however, that game theory assumes or neglects social structure (Bunge 1998), whereas the network approach we adopted in our study is mainly concerned with the effects of resource scarcity on social structure, and how social structure in turn might affect collective action.

\section{Social Capital, Collective Action, and Adaptive/ Proactive Resilience}

How do bonding, bridging, and linking social capital contribute to community resilience and collective action? Structurally, a network that has elements of bonding and bridging social capital appears more capable of building group resilience (Bodin et al. 2006), particularly when they encourage diversity and experimentation (Newman and Dale 2005). All our studied communities have elements of both bonding, bridging, and linking social capital that expand beyond kinship ties, which seems contrary to the common finding that Mexico 
is a "low trust" society, which places little trust outside family (Fukuyama 1995). Indeed, friendship ties are more numerous than kinship ties in the whole network. Yet, these communities have not developed their own institutions to control access to fishery resources, and government fisheries institutions have failed to prevent resource degradation (Ramirez-Sanchez 2007). It is possible then that the generalized fisheries decline in the area may have been exacerbated by the extent to which information is shared on the abundance and location of fish.

Thus, the significance of these networks for collective action is complicated. It has been pointed out that the significance of networks in the resilience of social-ecological systems is context dependent (Janssen et al. 2006). Social-capital researchers have also found evidence that networks and social capital useful in one context may not work in another (Hurlbert et al. 2001). The commercial fishers from the Loreto area have shown themselves to be capable of collective action in some contexts. In 1998, a mass resistance movement by fishers emerged in light of the provisions and restrictions on commercial fishing in the first management plan of the Loreto Bay National Marine Park. The overall effect was such that it took several years to find consensus on the management plan. Although it is not clear to what extent social networks played a role in this instance, it is likely that they were important in disseminating information to support this form of collective action. The restrictions and provisions of the management plan were understood by fishers as a direct threat to their livelihoods (Ramirez-Sanchez 2007). It appears then that such practical understanding (Schatzki 2002) was necessary for the information flowing through social networks to become meaningful and thus precipitate action. A similar argument has been made by Crona and Bodin (2006), who concluded that the absence of or weak bridging linkages among groups with different knowledge about the ecological condition of fisheries prevented the creation of common understanding for collective action in fisheries management and conservation in a rural fishing community in Kenya.

Interestingly, an understanding of the ecological situation seems to be present among fishers from Loreto. Although both the awareness of this problem and the network structure necessary for collective action seem to be present, it has not been mobilized for addressing resource decline. Indeed, what seems to be missing is an articulation of how fishers can change this situation. This situation appears to exemplify the distinction made by Newman and Dale (2005) between adaptive capacity and proactive resilience building and maintenance. In other words, the livelihoods of fishers from Loreto have adaptive capacity in dealing with fish fluctuations but little or no proactive resilience. The latter requires a more sophisticated understanding that cultivates diversity and encourages innovation and a precautionary approach (Newman and Dale 2005, Crona and Bodin 2006). To build proactive resilience, fishers from Loreto would need to become engaged in institutional building. An important insight emerging from this discussion is that such institutions would be more effective when built on existing social networks. Scholars and management authorities alike should recognize the existing and potential value of social networks.

\section{CONCLUSION}

There were six important findings from our study: (1) fishers' social networks within and between communities appear to be activated according to varying ecological conditions; (2) resource scarcity is an ambiguous indicator of the extent to which fishers share information on the abundance and location of fish within and between communities; (3) fishers' information sharing is based on trust, which is patterned by kinship, friendship, and acquaintance social relations; (4) friendship ties play a key role in fishers' social networks both within and between communities, surpassing kinship in constituting intercommunity ties; (5) the overall composition of fishers' social networks follows a friendship $>$ kinship >acquaintance order of importance; and (6) social ties, internal conflict, and settlement histories moderate the effects of resource scarcity on fishers' social networks.

Our findings show that high resource scarcity does not always decrease fishers' tendency to share information, and fishers' tendency to share information can be relatively low even in the absence of high resource scarcity. To be sure, fishers may share information extensively to find out about hot spots for fishing, even when resource abundance is relatively high because of the uneven distribution of fish. Kinship ties tend to dominate social networks at the community level, but the similarly strong friendship ties can be as important in the 
presence or absence of high resource scarcity. Acquaintance ties were relatively few or absent in small communities or those communities facing relatively low resource scarcity.

Our hypothesis that linking social capital is most likely to develop between a community facing high resource scarcity and a community with less resource scarcity problems was supported by our results. Linking social capital, however, is more widespread than we hypothesized and there were weak to medium links between communities facing relatively high resource scarcity, and a strong link between two of the communities experiencing higher fish abundance. The number instead of the presence of linking ties is likely to be an indicator of the extent to which fishers adopt geographic mobility as a coping strategy to deal with resource scarcity.

Our hypothesis that inter-community ties are more likely to be dominated by acquaintance ties than friendship and kinship ties was partially supported. Inter-community or linking ties were importantly constituted by acquaintance relations, which are mostly recognized for their utility in linking distinct groups rather than providing the immediate social and economic support supplied by kinship and friendship ties. However, friendship ties also play an important role in linking social capital.

The function of social ties, internal conflict and settlement histories are factors that help to explain the diverse impact that resource scarcity has on fishers' social capital. Indeed, fishers' networks in the Loreto area display complex patterns and are a pervasive feature of the way fishers are able to access fish. The number of ties reported by fishers is beyond any reasonable expectation given their knowledge on fish decline in the area. The emergent structure of the information-sharing networks of fishers from Loreto includes two elements arguably necessary for addressing fisheries management problems collectively: a combination of bonding, bridging, and linking ties as well as awareness of fisheries decline. Yet such collective action has not occurred. We propose that the livelihoods of fishers from the Loreto area show adaptive capacity to deal with resource fluctuations but they lack what resilient theorists have referred to as proactive resilience, which requires a more sophisticated understanding that embraces diversity, and encourages innovation and a precautionary approach. The existing social ties should, however, be considered a form of social capital which constitutes a foundational building block for the potential construction of proactive resilience.

Responses to this article can be read online at: http://www.ecologyandsociety.org/voll4/iss 1/art22/ responses/

\section{Acknowledgments:}

We would like to thank the International Development Research Centre (IDRC) and the Canon National Parks Science Scholars Program for supporting this research, and the fishers from Loreto who kindly agreed to participate in this research. We also thank three anonymous reviewers for their constructive suggestions, which improved the paper.

\section{LITERATURE CITED}

Acheson, J. M. 1981. Anthropology of fishing. Annual Review of Anthropology 10:275-316.

Allison, E. H., and F. Ellis. 2001. The livelihoods approach and management of small-scale fisheries. Marine Policy 25(5):377-388.

Andersen, R. 1972. Hunt and deceive: information management in Newfoundland deep-sea trawler fishing. Pages 120-140 in R. Andersen and C. Wadel, editors. North Atlantic fishermen: anthropological essays on modern fishing. Institute for Social and Economic Research (ISER), St. Johns, Newfoundland and Labrador, Canada.

Andersen, R., and C. Wadel. 1972. Comparative problems in fishing adaptations. Pages 141-165 in R. Andersen and C. Wadel, editors. North Atlantic fishermen: Anthropological essays on modern fishing. Institute for Social and Economic Research (ISER), St. Johns, Newfoundland and Labrador, Canada.

Aswani, S. 2002. Assessing the effects of changing demographic and consumption patterns on sea tenure regimes in the Roviana Lagoon, Solomon Islands. Ambio 31(4):272-284. 
Bebbington, A. 1999. Capitals and capabilities: a framework for analyzing peasant viability, rural livelihoods and poverty. World Development 27 (12):2021-2044.

Bodin, Ö., B. Crona, and H. Ernstson. 2006. Social networks in natural resource management: what is there to learn from a structural perspective? Ecology and Society 11(2): r2. [online] URL: http:/ /www.ecologyandsociety.org/vol11/iss2/resp2/.

Borgatti, S. P., M. G. Everett, and L. C. Freeman. 2002. UCINET for Windows: software for social network analysis. Analytic Technologies, Harvard University, Cambridge, Massachusetts, USA.

Borgatti, S. P., C. Jones, and M. G. Everett. 1998. Network measures of social capital. Connections 21 (2):27-36.

Bunge, M. 1998. Social science under debate: a philosophical perspective. University of Toronto Press, Toronto, Ontario, Canada.

Burt, R. S. 2001. Structural holes vs. network closure as social capital. Pages 31-56 in N. Lin, K. Cook, and R. S. Burt, editors. Social capital. Theory and research. Aldine De Gruyter, New York, New York, USA.

Carlsson, L., and A. Sandström. 2008. Network governance of the commons. International Journal of the Commons 2(1):33-54.

Crona, B., and Ö. Bodin. 2006. What you know is who you know? Communication patterns among resource users as a prerequisite for co-management. Ecology and Society 11(2): 7. [online] URL: http:// www.ecologyandsociety.org/vol11/iss2/art7/.

Crowe, J. A. 2007. In search of a happy medium: how the structure of interorganizational networks influence community economic development strategies. Social Networks 29:469-488.

Curran, S., and T. Agardy. 2002. Common property systems, migration, and coastal ecosystems. Ambio 31(4):303-305.

DaCosta, E., and Turner S. 2007. Negotiating changing livelihoods: the sampan dwellers of Tam Giang Lagoon, Viet Nam. Geoforum 38:190-206.

Fukuyama, F. 1995. Trust: the social virtues and the creation of prosperity. Free Press, New York, New York, USA.

Gatewood, J. B. 1984. Cooperation, competition, and synergy: information-sharing groups among Southeast Alaskan salmon seiners. American Ethnologist 11(2):350-370.

Gordon, H. S. 1954. The economic theory of a common-property resource: the fishery. Journal of Political Economy 62:124-142.

Grafton, R. Q. 2005. Social capital and fisheries governance. Ocean and Coastal Management 48:453-766.

Granovetter, M. 1973. The strength of weak ties. American Journal of Sociology 78(6):1360-1380.

Granovetter, M. 1983. The strength of weak ties: a network theory revisited. Sociological Theory 1:201-233.

Gutiérrez-Barreras, J. A. 2001. Reporte marino y costero del Municipio de Loreto, BCS, México. Grupo Ecologista Antares y Parque Nacional Bahía de Loreto. Loreto, Baja California Sur, México.

Hollister, J. 1996. Ensenada blanca: an understanding. Thesis, California State University, Chico, California, USA.

Hulbert, J. S., J. J. Beggs, and V. A. Haines. 2001. Social networks and social capital in extreme environments. Pages 209-232 in N. Lin, K. Cook, and R. S. Burt, editors. Social capital. Theory and research. Aldine de Gruyter, New York, New York, USA.

Instituto Nacional de Estadística y Geografía (INEGI). 2001. Tabulados Básicos Nacionales y por Entidad Federativa. Base de Datos y Tabulados de la Muestra Censal. XII Censo General de Población y Vivienda, 2000. Instituto Nacional de Estadística y Geografía, Aguascalientes, México.

Janssen, M. A., Ö. Bodin, J. M. Anderies, T. Elmqvist, H. Ernstson, R. R. J. McAllister, P. Olsson, and P. Ryan. 2006. A network perspective on the resilience of social-ecological systems. Ecology and Society 11(1): 15. [online] URL: http: //www.ecologyandsociety.org/vol11/iss1/art15/.

Johnson, J. C., and M. K. Orbach. 1990. 
Migratory fishermen: a case study in interjurisdictional natural resource management. Ocean and Shoreline Management 13:231-252.

Kadushin, C. 2004. Too much investment in social capital? Social Networks 26(1):75-90.

Klooster, D. 2000. Institutional choice, community, and struggle: a case study of forest co-management in Mexico. World Development 28(1):1-20.

Lin, N.2001. Building a network theory of social capital. Pages 3-30 in N. Lin, K. Cook, and R. S. Burt, editors. Social capital. Theory and research. Aldine de Gruyter, New York, New York, USA.

Leal-Jiménez, M. A., G. Arnaud-Franco, and G. Ramírez-García. 2003. Diagnóstico ambiental para la identificación de actividades productivas sustentables. Alianza por un Planeta Verde A. C. y Centro de Investigaciones Biológicas del Noroeste S. C. La Paz, BCS, México.

McCay, B. J. 1978. Systems ecology, people ecology, and the anthropology of fishing communities. Human Ecology 6(4):397-421.

McPherson, M., L. Smith-Lovin, and J. M. Cook. 2001. Birds of a feather: homophily in social networks. Annual Review of Sociology 27:415-444.

Morales-Polo, S. 1994. Loreto. Algunos hechos relevantes acerca de la historia del padre cultural de las Californias. Volume 1, Este es Loreto. Loreto, BCS, México.

Newman, L., and A. Dale. 2005. Network structure, diversity, and proactive resilience building: a response to Tompkins and Adger. Ecology and Society 10(1): r2. [online] URL: http:/ /www.ecologyandsociety.org/vol10/iss1/resp2/.

Noteboom, B. 2007. Social capital, institutions and trust. Review of Social Economy LXV(1):29-53.

Ostrom, E. 1990. Governing the commons: the evolution of institutions for collective action. Cambridge University Press, New York, New York, USA.

Portes, A. 1998. Social capital: its origins and applications in modern sociology. Annual Review of Sociology 24:1-24.
Plummer, R., and J. FitzGibbon. 2006. People matter: the importance of social capital in the comanagement of natural resources. Natural Resource Forum 30:51-62.

Pretty, J., and H. Ward. 2001. Social capital and the environment. World Development 29(2):209227.

Putnam, R. D. 1993. Making democracy work: civic traditions in modern Italy. Princeton University Press, Princeton, New Jersey, USA.

Ramirez-Sanchez, S. 2007. A social relational approach to the conservation and management of fisheries: the rural communities of the Loreto Bay national marine park, BCS, Mexico. Dissertation. Simon Fraser University, School of Resource and Environmental Management, British Columbia, Canada. [online] URL: http://www.rem.sfu.ca/pubs. htm.

Salas, S., and D. Gaertner. 2004. The behavioral dynamics of fishers: management implications. Fish and Fisheries 5:153-167.

Sanginga, P. C., R. N. Kamugisha, and A. M. Martin. 2007. The dynamics of social capital and conflict management in multiple resource regimes: a case of the southwestern highlands of Uganda. Ecology and Society 12(1): 6. [online] URL: http:// www.ecologyandsociety.org/vol12/iss1/art6/.

Schatzki, T. R. 2002. The site of the social. A philosophical account of the constitution of social life and change. The University of Pennsylvania Press, Philadelphia, Pennsylvania, USA.

Stiles, R. G. 1972. Fishermen, wives and radios: aspects of communication in a Newfoundland fishing community. Pages 35-60 in R. Andersen and C. Wadel, editors. North Atlantic fishermen: anthropological essays on modern fishing. Institute for Social and Economic Research (ISER), St. Johns, Newfoundland and Labrador, Canada.

Taylor, M., and S. Singleton. 1993. The communal resources: transaction costs and the solution of collective action problems. Political Sociology 21:195-215.

Truex, G. F. 1981. Kinship and network: a cognitive model of interaction. Social Networks 3(1):53-70. 
Appendix 1. Ratio values of the measured vs. the expected number of relations within (numbers in bold) and between communities using a relational contingency table analysis (Borgatti et al. 2002).

\begin{tabular}{|c|c|c|c|c|c|c|c|}
\hline \multirow[b]{2}{*}{ Community } & \multicolumn{7}{|c|}{ All Social Relations } \\
\hline & $\mathbf{A V}$ & $\mathbf{C Z}$ & EB & $\mathrm{JC}$ & LG & $\mathbf{N}$ & $\mathbf{R M}$ \\
\hline Agua Verde (AV) & 6.70 & 0.17 & 0.32 & 0.06 & 0.190. & 00 & 0.00 \\
\hline Colonia Zaragoza (CZ) & & 1.95 & 0.03 & 0.25 & 0.13 & 17 & 1.01 \\
\hline Ensenada Blanca (EB) & & & 7.81 & 0.00 & 0.59 & 88 & 0.00 \\
\hline Juncalito (JC) & & & & 6.30 & $0.56 \quad 0$. & 99 & 0.67 \\
\hline Ligüí (LG) & & & & & $\mathbf{7 . 5 3} 0$. & 98 & 0.00 \\
\hline San Nicolás (SN) & & & & & & 29 & 2.36 \\
\hline \multirow[t]{2}{*}{ Ramadita (RM) } & & & & & & & 12.14 \\
\hline & \multicolumn{7}{|c|}{ Kinship } \\
\hline Agua Verde (AV) & 8.33 & 0.06 & 0.40 & 0.13 & 0.00 & 0.00 & 0.00 \\
\hline Colonia Zaragoza (CZ) & & 1.37 & 0.00 & 0.12 & 0.04 & 0.03 & 0.36 \\
\hline Ensenada Blanca (EB) & & & 9.46 & 0.00 & 0.47 & 0.06 & 0.00 \\
\hline Juncalito (JC) & & & & 15.46 & 0.12 & 0.00 & 0.00 \\
\hline Ligüí (LG) & & & & & 9.76 & 0.00 & 0.00 \\
\hline San Nicolás (SN) & & & & & & 2.63 & 2.42 \\
\hline \multirow[t]{2}{*}{ Ramadita (RM) } & & & & & & & 14.49 \\
\hline & \multicolumn{7}{|c|}{ Friendship } \\
\hline Agua Verde (AV) & 6.19 & 0.22 & 0.20 & 0.00 & 0.20 & 0.00 & 0.00 \\
\hline Colonia Zaragoza (CZ) & & 2.69 & 0.07 & 0.24 & 0.20 & 0.09 & 0.86 \\
\hline Ensenada Blanca (EB) & & & 6.19 & 0.00 & 0.72 & 0.12 & 0.00 \\
\hline Juncalito (JC) & & & & 0.00 & 0.96 & 0.20 & 0.96 \\
\hline Ligüíi (LG) & & & & & 5.44 & 0.18 & 0.00 \\
\hline San Nicolás (SN) & & & & & & 6.52 & 2.63 \\
\hline \multirow[t]{2}{*}{ Ramadita (RM) } & & & & & & & 11.48 \\
\hline & \multicolumn{7}{|c|}{ Acquaintance } \\
\hline Agua Verde (AV) & 0.00 & 0.52 & 0.52 & 0.00 & 1.31 & 0.00 & 0.00 \\
\hline
\end{tabular}




\begin{tabular}{lcccccc}
\hline Colonia Zaragoza (CZ) & $\mathbf{1 . 2 1}$ & 0.00 & 1.18 & 0.24 & 1.57 & 6.13 \\
Ensenada Blanca (EB) & & $\mathbf{6 . 9 5}$ & 0.00 & 0.47 & 0.00 & 0.00 \\
Juncalito (JC) & & & $\mathbf{0 . 0 0}$ & 0.79 & 0.00 & 3.14 \\
Ligüí (LG) & & & $\mathbf{5 . 9 5}$ & 0.00 & 0.00 \\
San Nicolás (SN) & & & & & $\mathbf{0 . 0 0}$ & 0.00 \\
Ramadita (RM) & & & & & & $\mathbf{0 . 0 0}$ \\
\hline
\end{tabular}

